\title{
Impacts of Pore-Throat System on Fractal Characterization of Tight Sandstones
}

\author{
Dengke Liu $\mathbb{D}^{1,2}$ Zhaolin Gu, $^{1}$ Ruixiang Liang, ${ }^{3}$ Junwei Su, ${ }^{1}$ Dazhong Ren, ${ }^{4}$ Bin Chen, ${ }^{2}$ \\ Chuanqing Huang, ${ }^{5}$ and Chao Yang ${ }^{6}$ \\ ${ }^{1}$ School of Human Settlement and Civil Engineering, Xi'an Jiaotong University, Xi'an 710049, China \\ ${ }^{2}$ Shaanxi Key Laboratory of Petroleum Accumulation Geology, Xi'an Shiyou University, Xi'an 710065, China \\ ${ }^{3}$ No. 8 Oil Production Plant, Changqing Oilfield Company, PetroChina, Xi'an 710021, China \\ ${ }^{4}$ Shaanxi Key Laboratory of Advanced Stimulation Technology for Oil \& Gas Reservoirs, Xi'an Shiyou University, \\ Xi'an 710065, China \\ ${ }^{5}$ College of Chemistry and Chemical Engineering, Shaanxi University of Science and Technology, Xi'an 710021, China \\ ${ }^{6}$ Shaanxi Key Laboratory of Lacustrine Shale Gas Accumulation and Exploitation (Under Planning), Xi'an 710075, China \\ Correspondence should be addressed to Dengke Liu; liudengke02@126.com
}

Received 2 January 2020; Revised 6 May 2020; Accepted 22 May 2020; Published 18 June 2020

Academic Editor: Hui Pu

Copyright (c) 2020 Dengke Liu et al. This is an open access article distributed under the Creative Commons Attribution License, which permits unrestricted use, distribution, and reproduction in any medium, provided the original work is properly cited.

\begin{abstract}
The pore-throat structures play a dominant role in the evaluation of properties of tight sandstone, but it remains difficult to determine the related parameters and understand their impact on reservoir quality. Hence, toward this end, we analyze the experimental data that are indicative of the pore-throat system, then we investigate the effect of fractal dimensions of porethroat structures on petrologic and physical properties, and finally, the optical observations, fractal theory, and prediction model were integrated to explore the qualities of various reservoir types in tight sandstones. The results show that the fractal dimensions of the mercury intrusion curve correspond to three pore-throat types and those of the mercury extrusion curve could correspond to two pore-throat types. Five types of reservoirs were identified, the best reservoir type has a high percentage of interparticle and dissolution pores but a low proportion of clay-related pores, and the differences in pore-throat connectivity of various types affect storage capacity significantly. The storage ability prediction models of various reservoir types are raised by integrated experimental data. This work employed a comprehensive fractal theory based on capillary pressure curves and helps to explore how pore-throat systems influence reservoir quality in tight sandstones.
\end{abstract}

\section{Introduction}

Tight sandstones, as typical unconventional oil and gas resources, have a complex pore-throat network and strong heterogeneity due to complicated diagenetic alterations, and the characteristics of the pore size distribution (PSD) and pore structure have significant impacts on the behavior of reservoir quality [1-4]. Therefore, elucidating the features of pore-throat systems is vital for comprehending the mechanisms of hydrocarbon migration, accumulation, and distribution in tight sandstones. Fractal analysis can characterize the structures of various geometric pores and throats, in which the irregularity, instability, and strong heterogeneity of pore-throat systems could be quantified by fractal dimension $\mathrm{D}[5,6]$. Methods such as box-counting image, mercury intrusion (high pressure mercury intrusion porosimetry (HPMIP) and rate-controlled mercury porosimetry (RCP)), low-temperature gas adsorption (LTGA), and nuclear magnetic resonance (NMR) have been used frequently to investigate the fractal geometry of unconventional reservoirs [7-10]. The box-counting image could reveal the fractal dimension of pore-throat systems based on the two- 
dimensional observations (thin sections (TS), scanning electron microscopy (SEM)) or three-dimensional imaging (computerized tomography (CT)) [7, 11, 12]. However, it requires sufficient observation, and the accuracy is limited by the resolution of tiny pores and visual field. The RCP test can study the fractal features of pores and throats separately [3]; nevertheless, it is time consuming due to the requirement of quasistatic mercury intrusion (over five days for a single core sample). Furthermore, it can only quantify the heterogeneity of pores within the certain range of pore space and ignored some tiny pores and throats which have a major effect on percolation $[13,14]$, owing to the limited mercury intrusion pressure (maximum $6.2 \mathrm{MPa}$ corresponding to $0.12 \mu \mathrm{m}$ based on the Washburn equation [15]). LTGA analysis has been commonly acknowledged as a valid way of fractal characterization by the Frenkel-Halsey-Hill (FHH) model [16, 17]; nonetheless, this method would underestimate the pore scopes [18]. NMR is a lossless analytic test to ascertain the fractal characterization $[10,18]$, whereas it would record the information about noninterconnected pores because even isolated pores would be filled by simulated formation water in the saturation process, which may not be favorable for tight sandstone flow capability, thus providing inaccurate insight into the fractal characterization. Therefore, it is imperative to determine an appropriate way to calculate the fractal dimension in a wide range of PSD.

The HPMIP test is proposed to confirm features of pore-throat systems on a broad range of PSD, and this technique is generally accepted for its briefness, celerity, and authenticity in core experiments [8, 19]. Previous scholars have conducted the fractal analysis by the HPMIP method and discussed the correlations between the calculated fractal dimensions, physical properties, complexity, and heterogeneity of pore systems $[8,20]$. However, few researches have reported how mineral composition, especially clay minerals, influences the HPMIP curves in tight sandstones, and there is an obvious discrepancy in mercury imbibition and extraction regularity from interparticle pores, throats, and clay-related pores $[14,19]$. The previous studies about fractal characterization based on HPMIP method did not consider factors such as pore space classification based on topology; although the scale of intergranular and intragranular void spaces may be about the size, the seepage rule was different due to the multitype model [19]; hence, the HPMIP-derived fractal dimensions need to recalculate for a more realistic evaluation of heterogeneity and complexity of pore-throat systems quantitatively in tight sandstones. In this paper, the research was carried out by combining optical observations (thin sections and SEM), physical properties (porosity and permeability), and HPMIP tests on typical tight sandstones samples from the Ordos Basin, China. The fractal dimensions based on the multitype model were obtained from HPMIP, and its effect on mineral composition, physical properties, and characteristics of pore-throat systems were analyzed. The findings of this research are of great significance for quantificationally elucidating the pore-throat systems and pro- vide insight into industry engineering in tight sandstone reservoirs.

\section{Materials and Methodology}

2.1. Geological Setting and Sampling Sites. The Ordos Basin is a potentially promising tight sandstone play for hydrocarbon exploration and development, which is located in the eastern part of northwestern China and covers an area of about 2.5 $\times 10^{5} \mathrm{~km}^{2}[21,22]$. The study areas, which are located in the southwest of the Shanbei Slope Zone, are the most petroliferous first-class tectonic zones in the central areas of the Ordos Basin (Figure 1(a)) [23]. Triassic Yanchang Formation, which contains 10 oil-bearing members, was part of a lacustrine delta sedimentary system and controlled by northeast and southwest provenance $[21,22,24]$. A total of 30 specimens were obtained from Chang 6 and Chang 8 members which are oil-rich strata comprising the Yanchang Formation (Figure 1(b)).

2.2. Experimental Methods. In this research, the heliumbased porosity and nitrogen-based permeability tests were conducted by FYK-Iapparatus, manufactured by Nantong Feiyu Petroleum Technology Co., Ltd., under a confining pressure of $20 \mathrm{MPa}$. Red epoxy resin-impregnated thin sections were made for studying the petrology and pore systems were point-counted with at least 300 counts, using the Zeiss Axioskop II microscope. The spatial distribution of microspatial structures was analyzed using FEI Quanta 400 FEG scanning electron microscope (SEM). Besides, stub samples that were cut from the core plugs with the length of around $0.5 \mathrm{~cm}$ were analyzed using an X'Pert PRO energydispersive X-ray spectrometer to quantify the clay minerals. Finally, the samples were immersed into mercury for HPMIP tests by a Micromeritic Autopore IV 9420 Instrument, and the maximum injection pressure reached $200 \mathrm{MPa}$, corresponding to $3.675 \mathrm{~nm}$ according to Washburn's equation [15], and the results reported by Purcell [25] mean that it is able to detect a wide range of PSD in tight sandstones.

2.3. Methodology. The pore-throat systems in tight sandstones have a fractal property $(D)$, and this parameter corresponds to the complexity of the pore-throat structures; with the increase of $D$, the complexity of the pore throat also increases. The counted $N(>r)$, which corresponds to the void number with a radius over $r$, can be expressed by the following formula $[4,26]$ :

$$
N(>r)=\int_{r}^{r_{\max }} P(r) d r=r^{D},
$$

where $r_{\max }$ is the maximum pore radius, $\mu \mathrm{m}$, which corresponds to the minimum capillary pressure derived from HPMIP capillary curves. $P(r)$ refers to a pore radius density function, which represents the pore number with a radius, and has a negative relationship with the complexity of pore-throat structures. Then, for the integral equation mentioned above, we have 


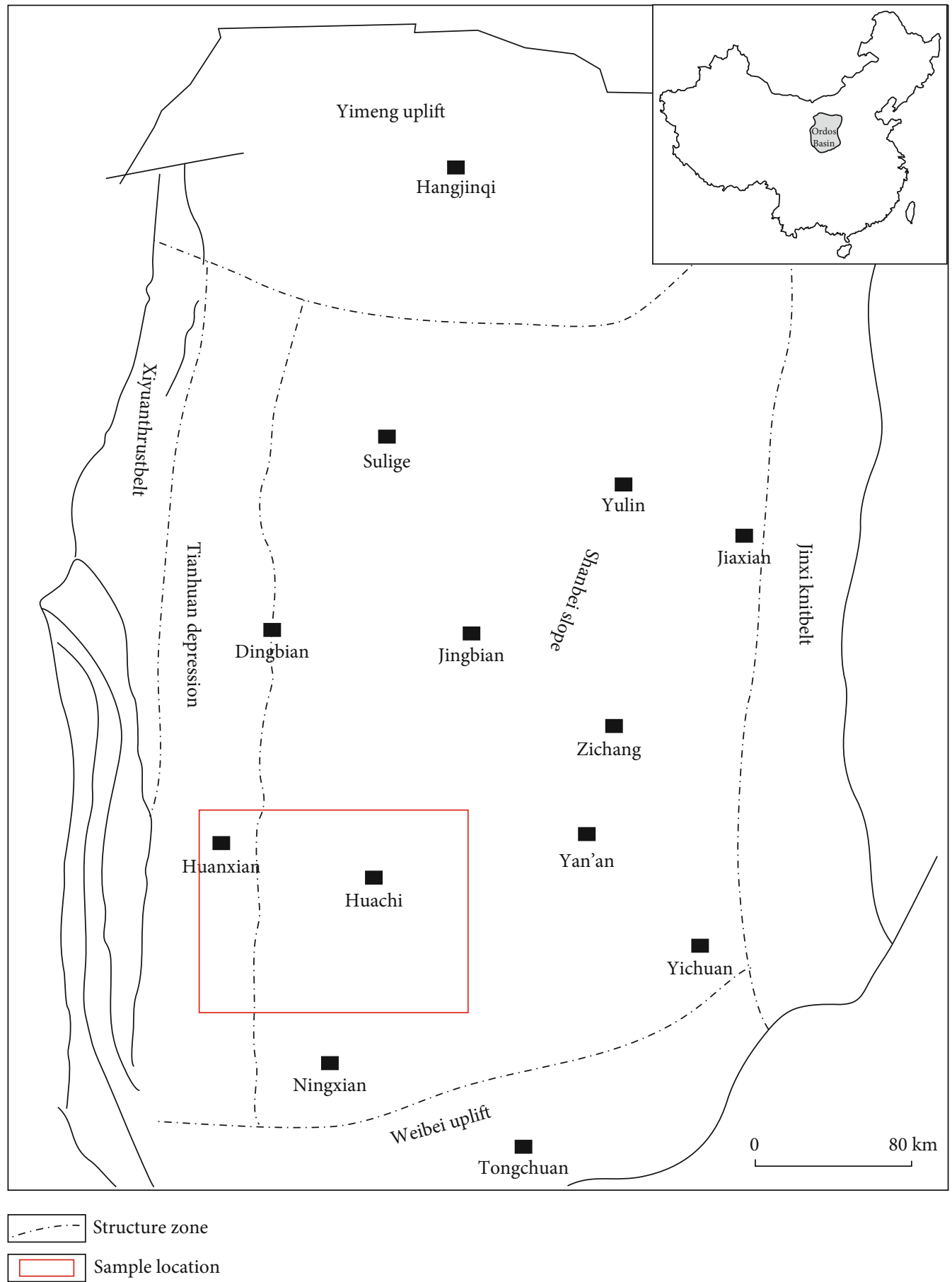

(a)

Figure 1: Continued. 


\begin{tabular}{|c|c|c|c|c|c|c|c|c|}
\hline System & Series & Formation & Member & Thickness & $\begin{array}{l}\text { Lithology } \\
\text { profile }\end{array}$ & $\begin{array}{l}\text { Main } \\
\text { source } \\
\text { rocks }\end{array}$ & $\begin{array}{l}\text { Main } \\
\text { reservoir } \\
\text { rocks }\end{array}$ & $\begin{array}{c}\text { Main } \\
\text { seal } \\
\text { rocks }\end{array}$ \\
\hline Jurasic & Lower & Fuxian & $\mathrm{J}$ & $0-130$ & 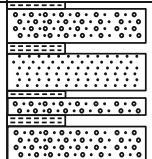 & & & \\
\hline \multirow{11}{*}{ Triassic } & \multirow{10}{*}{ Upper } & \multirow{10}{*}{ Yanchang } & Chang-1 & $70-90$ & 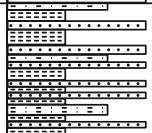 & & & \\
\hline & & & Chang-2 & $125-140$ & 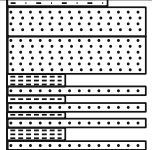 & & & \\
\hline & & & Chang-3 & $120-135$ & 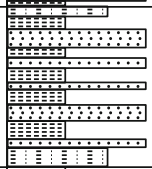 & & & \\
\hline & & & Chang $-4+5$ & $90-100$ & 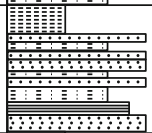 & & & \\
\hline & & & Chang-6 & $80-120$ & 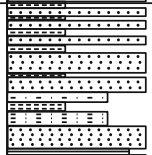 & & & \\
\hline & & & Chang-7 & $100-120$ & 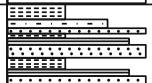 & & & \\
\hline & & & & & 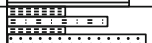 & & & \\
\hline & & & Chang-8 & $85-170$ & मी & & & \\
\hline & & & Chang-9 & $90-120$ & 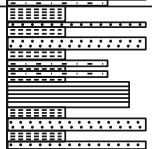 & & & \\
\hline & & & Chang-10 & 280 & 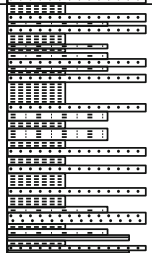 & & & \\
\hline & Meddle & Zhifang & $\mathrm{T}$ & $300-350$ & 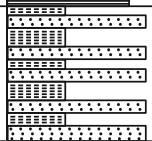 & & & \\
\hline
\end{tabular}

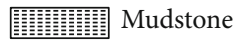

Sandy conglomerate

Sandstone

Esiltstone

(b)

FIGURE 1: (a) Location of the Ordos Basin concerning first-class tectonic elements of the Ordos Basin. (b) Stratigraphic column from Upper Triassic Yanchang Formation in Ordos Basin.

$$
P(r)=\frac{d N(>r)}{d r}=r^{-D-1}
$$

Thus, for the differential equation, we assumed that all the pores and throats are in cylindrical shapes; hence, the cumulative pore volume with a radius over $r[V(>r)]$ can be obtained:

$$
V(>r)=\int_{r}^{r_{\max }} P(r) \pi \alpha d r
$$


$\alpha=r^{2} l$, where $l$ is the cylinder length and $r$ is regarded as a radius in this case $[27,28]$, and we assumed that the cylinder length is proportional to the radius, then the cumulative pore volume can be written as

$$
V(>r)=\int_{l}^{l_{\max }} \int_{r}^{r_{\max }} P(r) \pi r^{2} l d r=\int_{r}^{r_{\max }} P(r) \pi r^{3} d r .
$$

The following formula could be obtained by substituting Equation (2) into Equation (4):

$$
V(>r)=\int_{r}^{r_{\max }} r^{-D-1} \cdot \pi r^{3} d r=\int_{r}^{r_{\max }} \pi r^{2-\mathrm{D}} d r=r_{\max }^{3-D}-r^{3-D} .
$$

Then, the total pore volume could be acquired:

$$
V=r_{\max }^{3-D}-r_{\min }^{3-D}
$$

The mercury intrusion saturation, which corresponds to the saturation with capillary pressure derived from HPMIP tests, could be calculated using the following formula:

$$
1-S_{\mathrm{Hg}}(>r)=\frac{V(<r)}{V}=\frac{\left(r^{3-D}-r_{\min }^{3-D}\right)}{\left(r_{\max }^{3-D}-r_{\min }^{3-D}\right)} .
$$

The minimum value can be omitted compared with the maximum radius due to the huge difference; Equation (7) then be written as

$$
1-S_{\mathrm{Hg}}(>r)=\frac{\left(r^{3-D}-r_{\min }^{3-D}\right)}{r_{\max }^{3-D}}=\left(\frac{r}{r_{\max }}\right)^{3-D}-\left(\frac{r_{\min }}{r_{\max }}\right)^{3-D}=\left(\frac{r}{r_{\max }}\right)^{3-D} .
$$

Based on the Washburn equation [15], Equation (8) can be written as

$$
1-S_{\mathrm{Hg}}(>\mathrm{r})=\left(P_{c}-P_{\min }\right)^{D-3},
$$

where $P_{\min }$ is the threshold pressure, which corresponds to the nonzero signal from capillary curves from HPMIP tests, taking the logs of both sides:

$$
\lg \left(1-S_{\mathrm{Hg}}(>r)\right)=(D-3) \lg P_{c}-(D-3) \lg P_{\min } .
$$

Equation (10) could be used to determined $D . \lg \left(P_{c}\right)$ was used as the $x$-axis and $\lg \left(1-S_{\mathrm{Hg}}(>r)\right)$ was used as $y$-axis, then

$$
D-3=k
$$

\section{Results}

3.1. Petrographic Mineralogy. The selected 16 tight sandstone samples varied from arkose to lithic arkose with quartz, feldspar, and rock fragments (Supplementary Table 1, Figure 2(a)). Besides, the samples were rich in metamorphic rock fragments (av. 9.31\%), followed by igneous rock fragments (av. 6.31\%) and sedimentary rock fragments (av. $1.94 \%)$. Clay minerals, authigenic quartz, and carbonate minerals were the mainly interstitial filling, attributable to the diagenetic process after the sedimentary stage, and account for $6.00 \%$ to $12.00 \%$, with an average of $10.45 \%$ (Supplementary Table 1). Illite is the predominant clay minerals in the research regions and are at intervals on the basis of XRD data, followed by chlorite and illite/smectitemixed layer, while the content of kaolinite is minor (Supplementary Table 2). The point-counted analysis reveals that the sorting in Yanchang Formation sandstones were primarily moderate and poorly sorted, while the roundness is mainly subangular (Figures 2(b) and 2(c)).

3.2. Physical Properties. The physical property results of 16 tight sandstone samples show that the porosity ranges from $4.33 \%$ to $12.39 \%$, with an average of $9.43 \%$, and the permeability is mainly between 0.040 and $1.244 \mathrm{mD}$, with an average of $0.463 \mathrm{mD}$ (Supplementary Table 1; Figure 3). The correlation coefficient of the samples manifests that the core-analyzed porosity is in good agreement with the coreanalyzed permeability, with an $R$-squared of 0.8085 (Supplementary Table 1; Figure 3).

3.3. Pore-Throat System and HPMIP-Derived Fractal Dimensions. Basically, the pore-throat system could be characterized by the pore-throat structure and PSD, which were represented by some parameters, such as threshold pressure, median pressure, maximum mercury saturation, sorting coefficient, and mercury withdrawal efficiency. The entry pressure, which was determined by the point on the capillary curve at which the nonwetting phase (mercury) intrudes into the pores of the samples originally, is in a range of 0.07 $7.39 \mathrm{MPa}$, with an average of $1.28 \mathrm{MPa}$. The point on the capillary curve where mercury saturation is at $50 \%$ is the median pressure, with values which range from 0.68 to $97.00 \mathrm{MPa}$ (av. 15.22 MPa) in Yanchang Formation tight sandstones. The maximum mercury saturation is the point corresponding to $200 \mathrm{MPa}$ capillary pressure in this case, and it ranges from $57.03 \%$ to $97.01 \%$ with a mean value of $85.44 \%$. Sorting coefficient is the indicator of pore-throat heterogeneity, and the values which are in a range of 1.90-4.45, with an average of 2.56, reveal that the sorting of Yanchang Formation tight sandstones is poor. Furthermore, the mercury withdrawal efficiency is calculated as $18.09 \%-41.68 \%$, with a mean value of $28.36 \%$. Skewness varies from 0.63 to 2.01 , with an average of 1.62. Meanwhile, mercury extrusion-derived threshold pressure, corresponding to the initial inflection point of the extrusion capillary pressure curves, ranged from 54.71 to $184.83 \mathrm{MPa}$ (av. 128.80 MPa). The results are all expressly presented in Supplementary Table 3 and Figure 4.

Fractal dimensions of 16 tight sandstone specimens from the research area were obtained from the $\log \left(1-S_{\mathrm{Hg}}\right)-\log \left(P_{\mathrm{c}}\right)$ plot (Figure 4) derived from HPMIP data, and all samples were in accordance with Formulas (9) and (11) which reveal the pore-throat fractal dimensions of each specimen. As shown in Figure 4 and Supplementary Table 3, the fractal dimension of pore throats could be divided into five ranges; $D_{i 1}, D_{i 2}$, and $D_{i 3}$ are in accordance with ascending capillary 


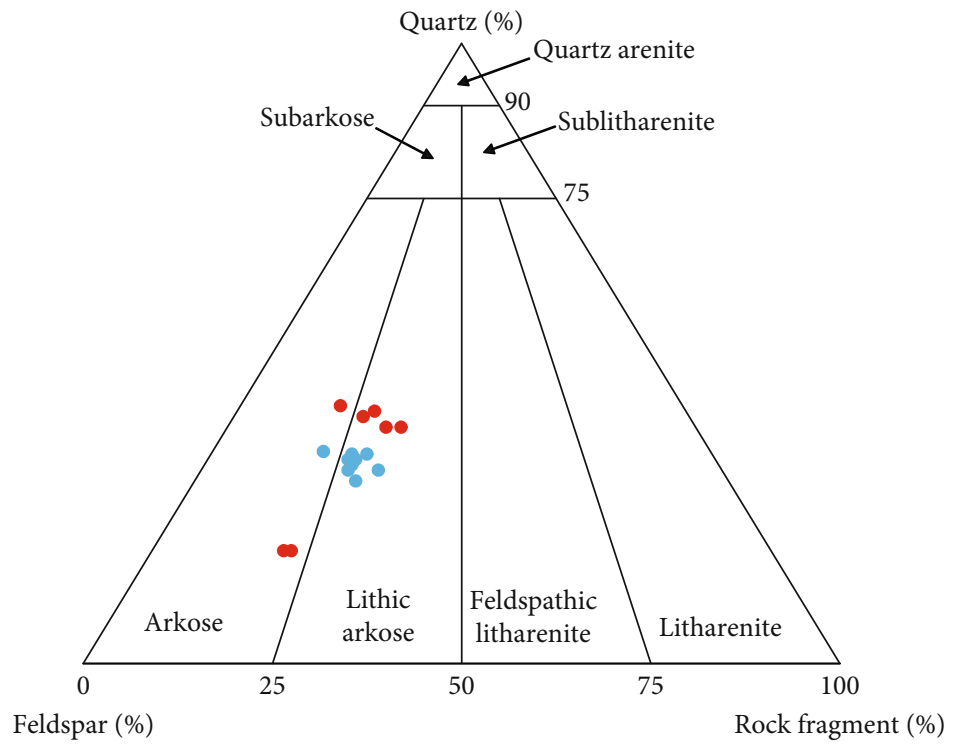

- $\mathrm{C6}$

- $\mathrm{C} 8$

(a)

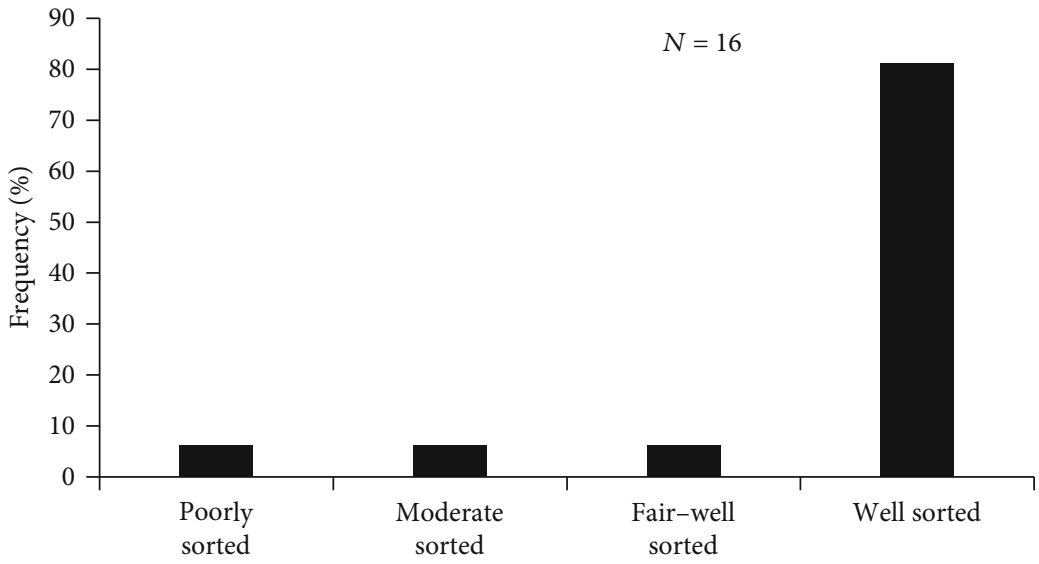

(b)

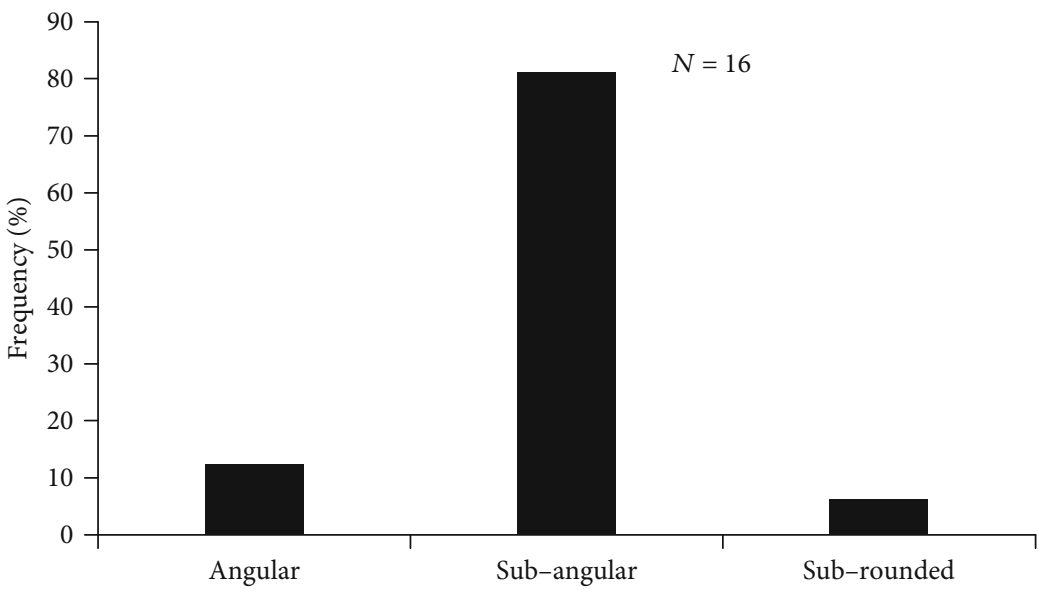

(c)

FIGURE 2: Petrographic characteristics of tight sandstone reservoirs in Ordos Basin. (a) Classification of tight sandstones on a basis of Folk's methods [29]; (b) sorting distribution; (c) roundness distribution. 


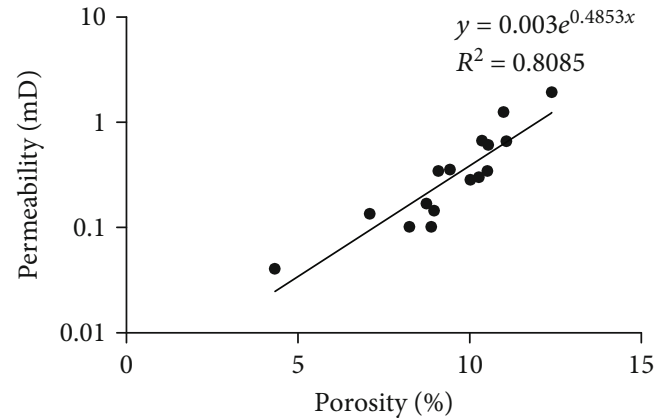

FIGURE 3: Porosity versus permeability of tight sandstones in the Ordos Basin.

pressure based on the mercury intrusion curves; accordingly, $D_{e 1}$ and $D_{e 2}$ are with respect to descending capillary pressure based on the mercury extrusion curves. The intrusion curvederived fractal dimensions $\left(D_{i 1}, D_{i 2}\right.$, and $\left.D_{i 3}\right)$ varied from 2.406 to 2.901 (av. 2.666), 2.351 to 3.415 (av. 2.667), and 1.878-2.865 (av. 2.499) and the extrusion curve-derived fractal dimensions $\left(D_{e 1}\right.$ and $\left.D_{e 2}\right)$ in a range of 2.266-2.957 (av. 2.731) and 2.695-2.987 (av. 2.833), and all correlation coefficients of calculated fractal dimension results are over 0.90 , manifesting that the samples can be characterized by fractal geometry theory (Supplementary Table 4). These phenomena reveal that five fractal dimensions may be able to confirm the fractal characterization of tight sandstones.

\subsection{Space Characterization Based on Microscopic Observations} Combined with Fractal Theory. The spaces in tight sandstones with self-similarity are characterized by similar structures at various pore-throat scales and exhibited a representative linear relationship on a $\log \left(1-S_{\mathrm{Hg}}\right)-\log \left(P_{c}\right)$ plot on a basis of fractal theory [27, 30-32]. Hence, the characteristics of void space in tight sandstones are diverse, which can be reflected as a multiple segment of capillary pressure curves and different genetic types using petrographic observations and a multitype model proposed by Sakhaee-Pour and Bryant [19]. Four types of pores were identified by TS observations in tight sandstones from the Yanchang Formation, Ordos Basin, including interparticle pores, dissolution pores, narrowed pores, and clay-related pores (Figure 5(a)) (net region represents the area that mercury occupied at this stage). The interparticle pores, which are usually in a triangular shape with smooth edges, represent the spaces among few detrital grains, the size of which are relatively large (primary between 10 and $200 \mu \mathrm{m}$ in diameter), corresponding to the $D_{i 1}$ fractal dimension generally (Figures 4 and 5(a)). Mercury mainly invades interparticle pores at this relatively low pressure (Figures 5(a) and 5(b)). Dissolution pores usually originated from dissolved detrital grains and were characterized by irregular pore shapes and an uneven surface, with pore sizes ranging from $0.5 \mu \mathrm{m}$ to $100 \mu \mathrm{m}$ (Figure 5(a)). The discrepancy between the morphology of dissolution pores and interparticle pores reveals that the fractal dimensions of the first mentioned of two are usually different from the latter, corresponding to the $D_{i 2}$ on account of relatively small pore size (corresponding to larger capillary pressure) (Supplementary
Table 4, Figure 4), and at this pressure, the mercury would invade into the dissolution pores and formed the nonwetting phase cycle (Figures 5(c) and 5(d)). Narrowed pores, in essence, are throats, which linked with relatively large pores at both ends (Figure 5(a)). Throats are not the significant storage spaces but the crucial flowing pathways for tight sandstones and made great contributions to the percolation $[14,27]$. Clay-related pores are broadly distributed in clay mineral aggregates, and the sizes of these pores are usually less than $5 \mu \mathrm{m}$ (Figure $5(\mathrm{a})$ ). The volumes and sizes of clay-related pores are sufficiently small compared with the narrowed pores (Figure 5(a)); however, the open porosity contributed by clay aggregates associated with the aluminosilicate fraction can compensate for the loss of porosity that was caused by clay mineral obstruction, and they exhibit similar shapes $[33,34]$; thus, $D_{i 3}$ fractal dimensions are considered to be the representative of the combination of narrowed pores and clay-related pores (Figure 4). Therefore, the capillary pressure is sufficient for the intrusion of nearly all of the pore-throat network (Figures 5(e) and 5(f)); meanwhile, the clay-related pores, which are characterized by a tree-like model, stop preventing the mercury from reaching the pore throat at larger pressures (Figures $5(\mathrm{~g})$ and $5(\mathrm{~h})$ ). In the process of mercury extrusion, the mercury would leave the smallest pores (clay-related pores in this case) initially (Figures 5(i) and $5(\mathrm{j}))$, then leave the throats and pores that exist in the interconnected path to the outside (Figures 5(k) and 5(l)). Therefore, the mercury extrusion-derived fractal results can be summarized as follows: $D_{e 1}$ reflects the fractal dimensions of the clay-related pores, and the fractal dimensions of the mercury withdrawal continued as we lower the capillary pressure $\left(D_{e 2}\right)$ which can indicate the characterization of throats and smaller pores that are connected to the outside (Figure 4).

\section{Discussion}

4.1. Analysis of Pore-Throat Structure with Fractal Dimensions. In order to ascertain the effects of fractal dimensions on networks, the correlations between fractal dimensions and the typical parameters of pore-throat structures were studied using Microsoft Excel software. The correlation coefficients of the typical parameters related to pore-throat structures and fractal dimensions are listed in Supplementary Table 5 and imaged in Figure 6. Computational results reveal that, compared with other fractal dimensions, $D_{e 2}$ and $D_{i 1}$ have relatively good negative correlations with threshold radius, median radius, and especially average radius, which means that the pore throats with good connectivity are sensitive indicators for pore-throat radius. A lower radius represents finer pores, and great fractal dimensions indicate inhomogeneous pore-throat distribution; thus, these inverse correlations attest that the interparticle pores with higher heterogeneity and complexity can decrease the pore-throat radius because of the rough surfaces and complex structure and made less mercury withdrawal in the progress of extrusion due to the enhanced capillary pressure. 


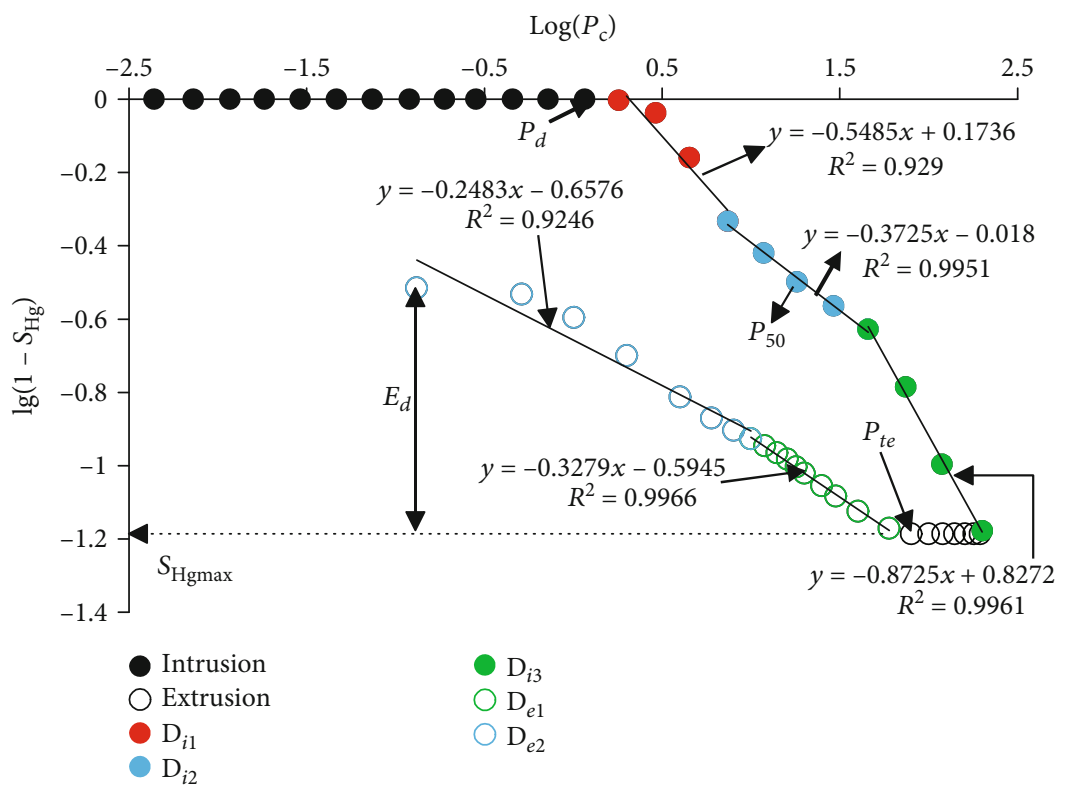

FIgURE 4: Representative parameters and fractal dimensions from $\lg \left(P_{c}\right)$ vs. $\lg \left(1-S_{\mathrm{Hg}}\right)$ using HPMIP. $d$ : entry pressure; $P_{50}$ : median pressure; $S_{\mathrm{Hgmax}}$ : maximum mercury saturation; $E_{d}$ : mercury withdrawal efficiency.

Fractal dimensions $D_{e 1}$ and $D_{e 2}$ show median and strong negative relationship with the maximum mercury saturation, respectively, while the correlations between maximum mercury saturation and $D_{i 1}, D_{i 2}$, and $D_{i 3}$ are vague (Supplementary Table 5; Figure 6). It is consequently suggested that heterogeneous structures of the interconnected pores and the development of clay minerals have a detrimental effect on storage. Besides, it can be also inferred that $D_{e 2}$ should be a better representative of the storage capacity of tight sandstones because of the high sensitivity to the maximum mercury saturation, and the clay-related pores have great impacts on the whole pore-throat volumes in tight sandstones due to its higher proportion.

Fractal dimensions $D_{i 3}, D_{e 1}$, and $D_{e 2}$, to a certain degree, are negatively correlated with the efficiency of mercury withdrawal, and the relationships between $D_{i 1}$ and the efficiency of mercury withdrawal are rarely noticeable; however, $D_{i 2}$ shows a positive correlation with the efficiency of mercury withdrawal (Supplementary Table 5; Figure 6). The efficiency of mercury withdrawal can be seen as a proxy for producibility of reservoirs [19], so the results show that it depends on the clay-related pores and the pore throats that have great connectivity. Besides, dissolution pores compensate for the loss of storage and show a similar pattern of results as previous research [35].

There are positive relationships between sorting coefficients and all the fractal dimensions, and the impact of $D_{e 2}$ is the most significant (Supplementary Table 5; Figure 6). This phenomenon may be attributable to the fact that the sorting coefficient is a valid parameter to evaluate the complexity of pore-throat structures, especially for those well-interconnected pores. The correlations between skewness and fractal dimensions are hardly shown (Supplementary Table 5; Figure 6), indicating that the percentage of large pores is not the principal element that determines the heterogeneity of pore throats in tight sandstones. The correlation coefficients of sorting coefficients and fractal dimensions surpass that of skewness and fractal dimensions, manifesting that the fractal dimensions are more favorable for the evaluation of smoothness and heterogeneity of tight sandstones but hardly reflect the skewness.

4.2. Influence of Mineral Compositions on Fractal Dimensions. The main mineral compositions which may control the fractal dimensions of pore-throat systems in the tight sandstones are volcanic rock fragments, illite, and carbonate minerals (Supplementary Table 6; Figure 7). Quartz, feldspar, and other rock fragments have minor effects on fractal dimensions, which mean that the detrital grains were not the dominant factors on pore-throat systems. Volcanic rock fragments exhibit a negative impact on the $D_{e 1}$ while the illite shows a positive correlation with $D_{i 1}, D_{i 3}$, and $D_{e 1}$ (Supplementary Table 6; Figure 7). The volcanic rock fragments were one of the main origins of smectites, and the smectites were easily transformed to illite through mixed-layer I/S [36]; thus, the proportion of the volcanic rock fragments would decrease with the increase of the illite. Hence, the illite is one of the main mineral factors responsible for the increase of fractal dimensions in tight sandstones. The positive correlations between the illite and $D_{i 1}$ suggest that the illite occludes the pores partly and bridges the pores that enhanced the complexity of porethroat structures (Supplementary Table 6; Figure 7). The positive relationships between illite and $D_{i 3}$ and $D_{e 1}$ reveal that not only macropores and mesopores but also the clayrelated pores and throats become irregular with the increase of the illite (Supplementary Table 6; Figure 7). Carbonate 


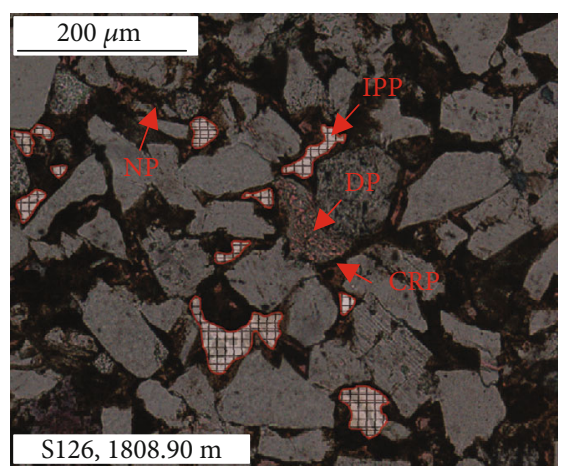

(a)

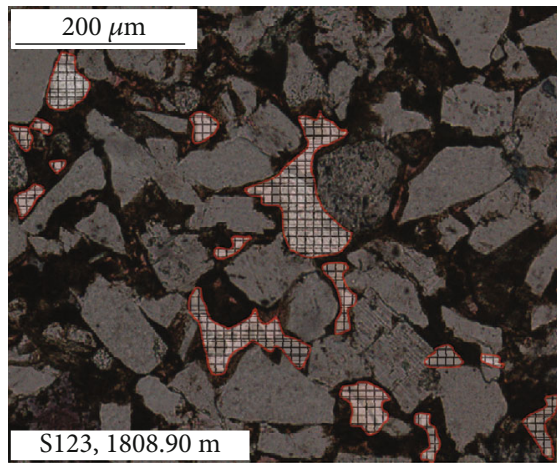

(c)

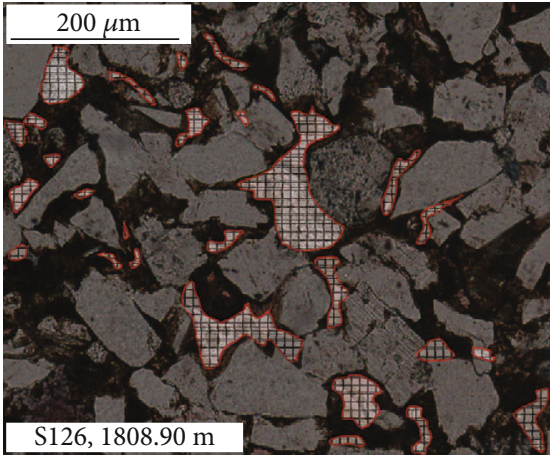

(e)

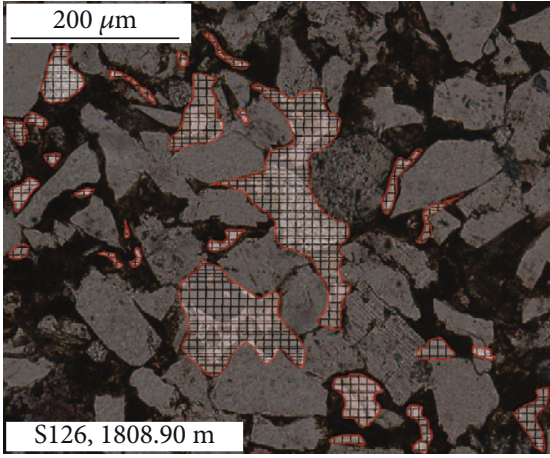

(g)

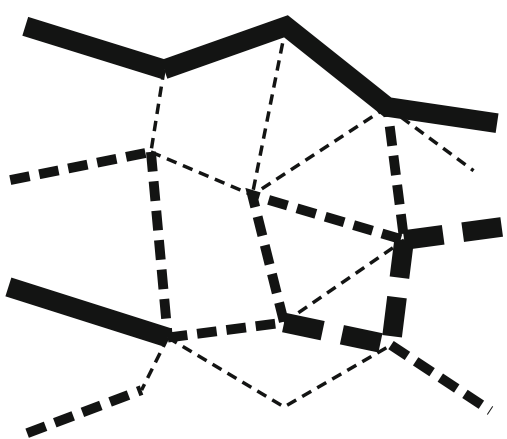

(b)

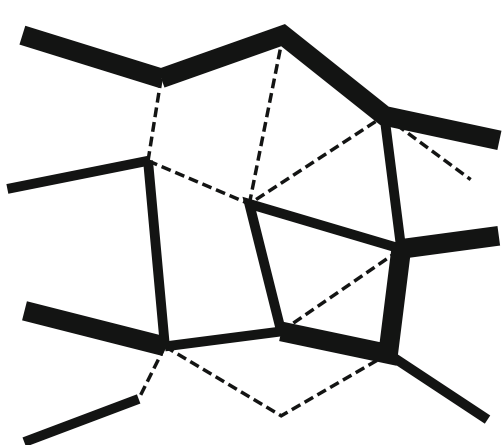

(d)

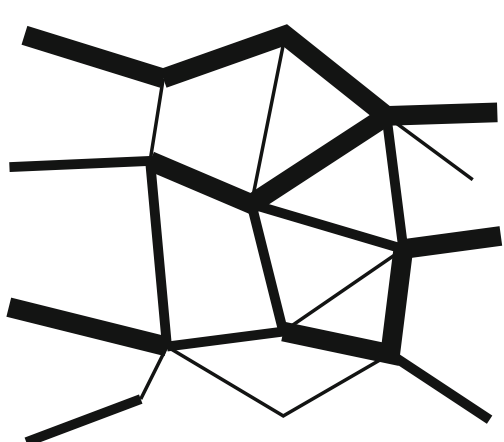

(f)

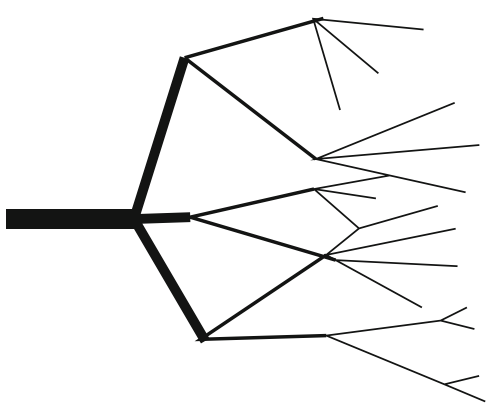

(h)

Figure 5: Continued. 


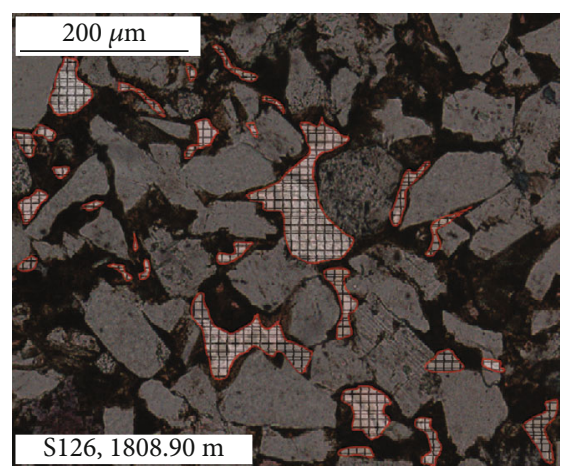

(i)

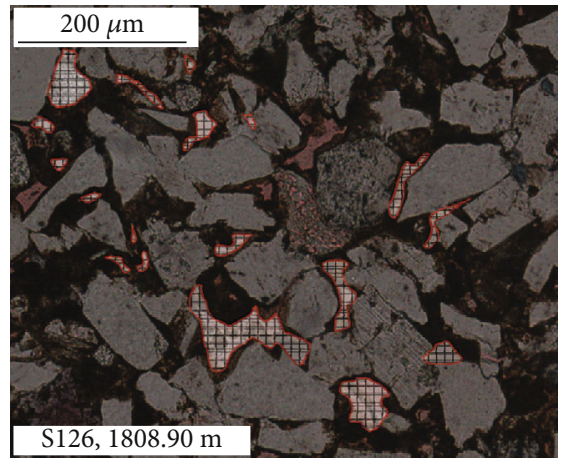

(k)

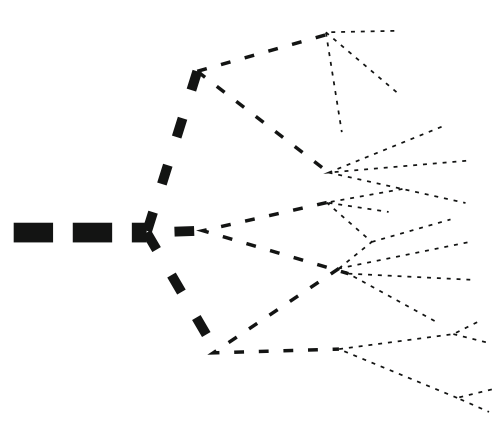

(j)

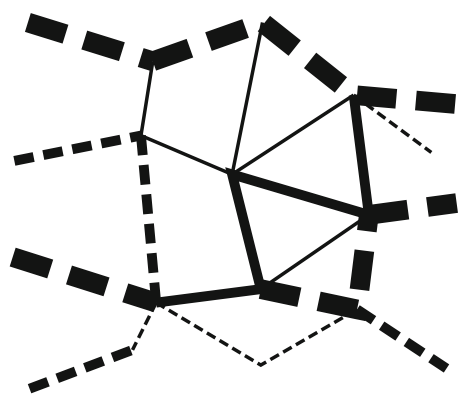

(1)

FIGURE 5: TS observations and multitype model (solid line represents mercury filling the voids, dashed line represents wetting phase filling the voids, and line thickness represents the diameters of pore throats).

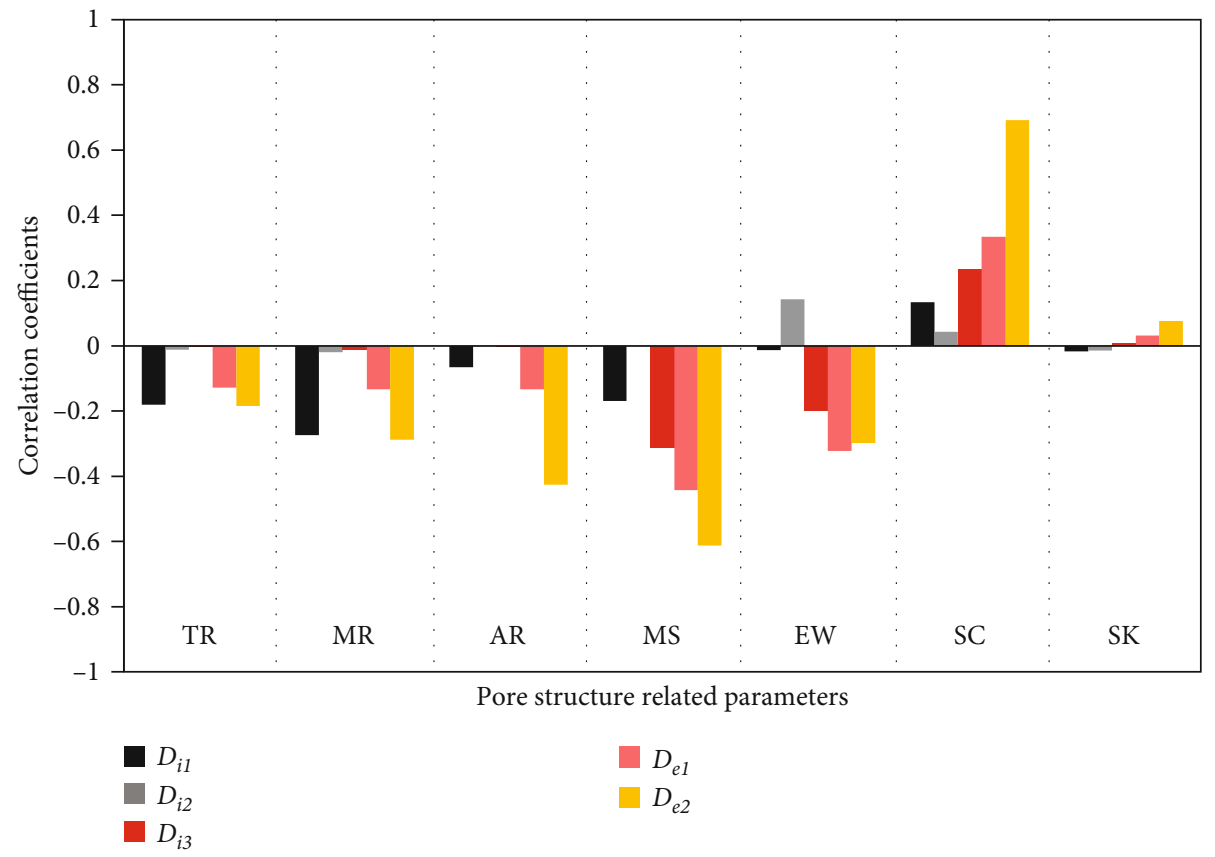

FIGURE 6: Correlation coefficients of the typical parameters related to pore-throat structures and fractal dimensions. Positive values mean positive relationships, while negative values represent a negative correlation. TR: threshold radius; MR: median radius; AR: average radius; MS: maximum mercury saturation; EW: efficiency of mercury withdrawal; SC: sorting coefficient; SK: skewness. 


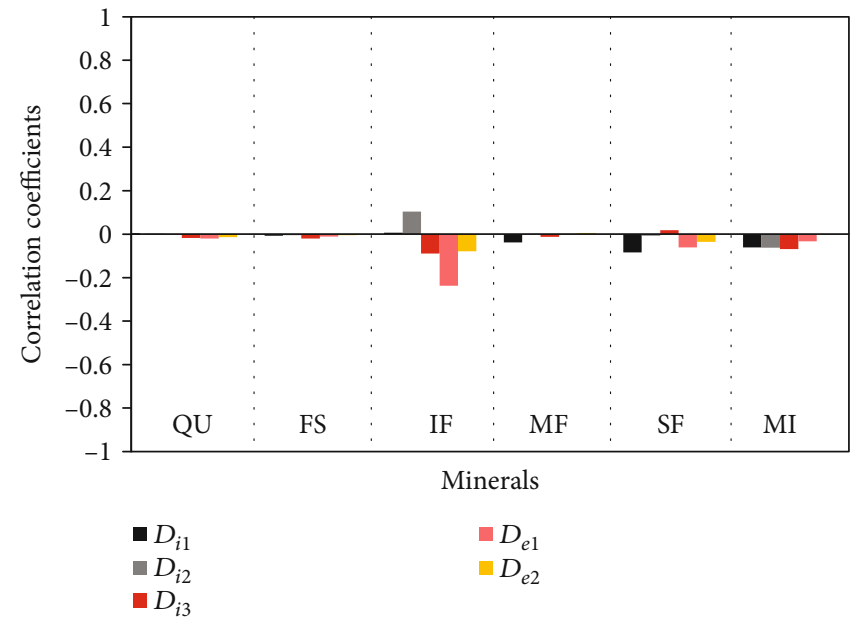

(a)

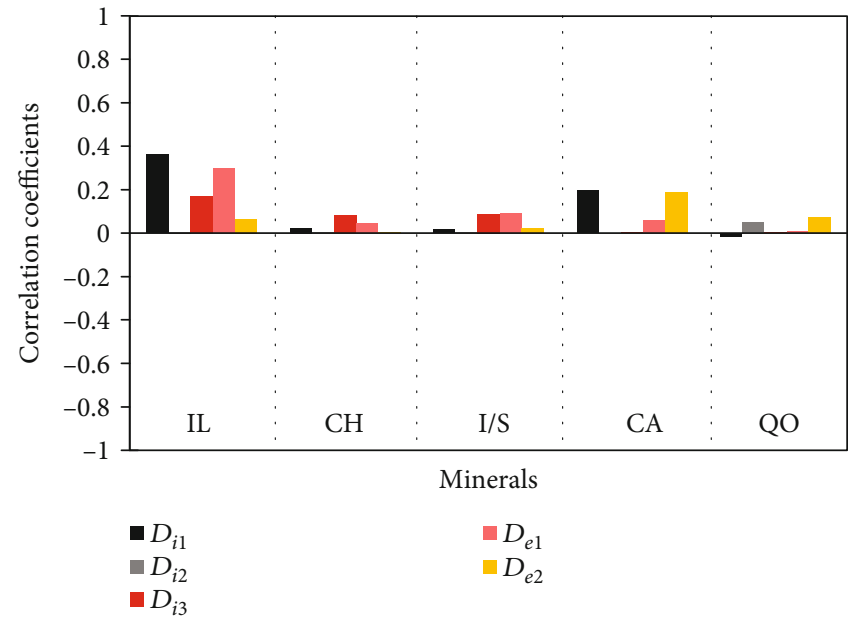

(b)

Figure 7: Correlation coefficients of the (a) skeleton particles and (b) interstitial minerals and fractal dimensions. Positive values mean positive relationships, while negative values represent a negative correlation. QU: quartz; FS: feldspar; IF: igneous rock fragments; MF: metamorphic rock fragments; SF: sedimentary rock fragments; MI: mica; IL: illite; CH: chlorite; I/S: I/S mixed layer; CA: carbonate; QO: quartz overgrowth.

minerals played a subordinate role in increasing the fractal dimensions due to the relatively low absolute content compared with the illite. Carbonate exerts a positive correlation with the $D_{i 1}$ and $D_{e 2}$ owing to their occurrence as the products of cementation and deteriorates the porethroat connection by occluding pore throats (Supplementary Table 6; Figure 7).

4.3. Impacts of Fractal Dimensions on Physical Properties. $D_{i 1}$, $D_{e 1}$, and $D_{e 2}$ have negative correlations with the porosity, while the relationships between $D_{i 2} / D_{i 3}$ and porosity are not obvious (Supplementary Table 7; Figures 8(a)-8(e)). These indicate that the interparticle pores and clay-related pores played an important role in affecting the porosity because of the massive storage space. Permeability also has negative correlations with $D_{i 1}, D_{e 1}$, and $D_{e 2}$; however, the $R$ -squared of permeability versus $D_{e 2}$ is relatively high compared with other parameters, indicating that the wellinterconnected pores were more sensitive to the permeability when compared to the porosity in tight sandstones (Supplementary Table 7; Figures 8(f)-8(j)).

\subsection{Classification of Reservoirs Based on Fractal Geometry.} Microscopic observations are effective ways for pore-throat type determination. However, due to the resolution of these methods and the restricted spatial field of view, the space types recognized by optical observations were ambiguous and circumscribed to a certain degree. Therefore, it is vital to input the pore types to the total sandstone spaces and classify the reservoir types according to the percentage of different kinds of reservoir voids via optical observations associated with the HPMIP-derived curves. Based on these principles, five communities of reservoir types were classified, namely, interparticle pore-dominated, dissolution pore-dominated, throat-dominated, clay-related pore-dominated, and tight type.
For the interparticle pore-dominated reservoir type, micro reservoir spaces are mainly interparticle pores associated with some moldic pores (Figure 9(A-1)). The reservoir quality of this reservoir type is the best with the highest porosity and permeability $(12.39 \%$ and $1.929 \mathrm{mD}$ in the typical sample, respectively) (Figure 10). The fractal dimensions of different pore types corresponding to the mercury intrusion curves have small differences in values, and they exert a nonpercolation stage (long tail in the mercury intrusion curve) due to the relatively low content of interstitial minerals, namely, the contribution of void spaces among clay aggregates to storage is minimal, and carbonate has less effect on the hydrocarbon accumulation ability (Supplementary Table 4; Figures 9(A-2) and 9(A-3)). The distances of $D_{i 1}$ and $D_{i 2}$ show greater length $(30.56 \%$ and $28.97 \%$, respectively), and the inflection points of mercury intrusion curve correspond to relatively large mercury saturation, revealing that interparticle pores are dominant and dissolution pores are subdominant spaces in these reservoir types (Supplementary Table 8; Figures 9(A-3) and 9(A-4)). The entry pressure of the mercury intrusion curve shows a low value due to the massive macropores, and the relatively low initial mercury withdrawal pressure attested that there were few mercury expelled from the cores in this process according to the treelike model $[19,37]$ owing to the insufficiency of the clay minerals, and the low hysteresis of the curves demonstrates the considerable mercury withdrawal from the samples due to the good pore-throat connectivity (Supplementary Table 4; Figures 9(A-3) and 9(A-4)).

Dissolution pores are quite common in a dissolution pore-dominated reservoir type, and hence, kaolinite which is derived from feldspar dissolution is easily visible within pore voids [38-40] (Figures 9(B-1) and 9(B-2)). The porosity and permeability of this type are still relatively high (Figure 10 ), $10.54 \%$ and $0.606 \mathrm{mD}$ in the typical sample, respectively. According to the mercury curve, the interparticle 


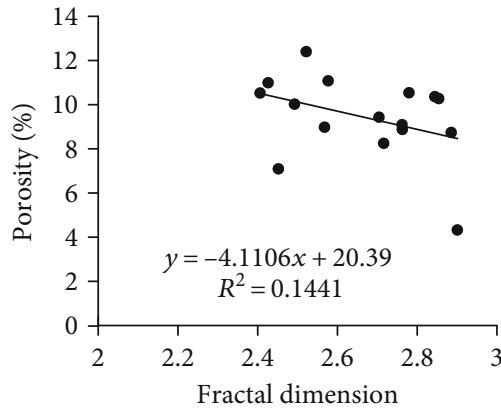

(a)

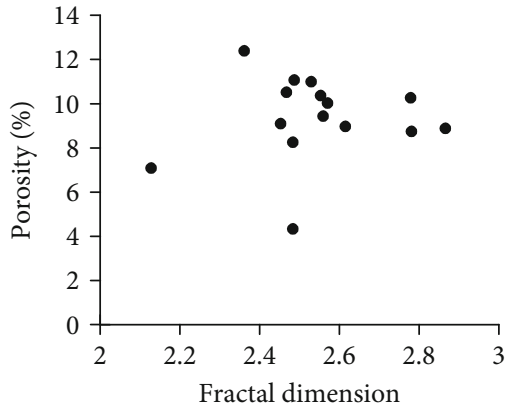

(c)

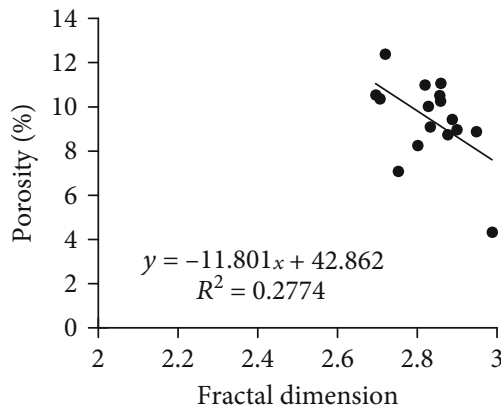

(e)

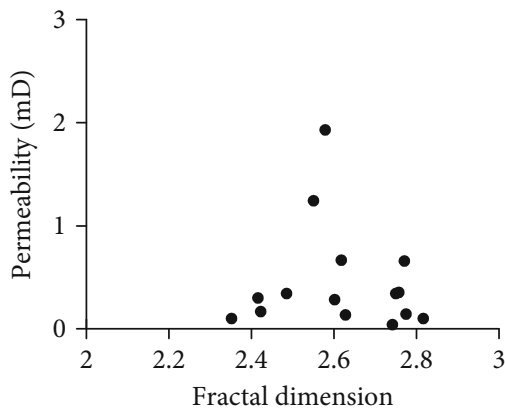

(g)

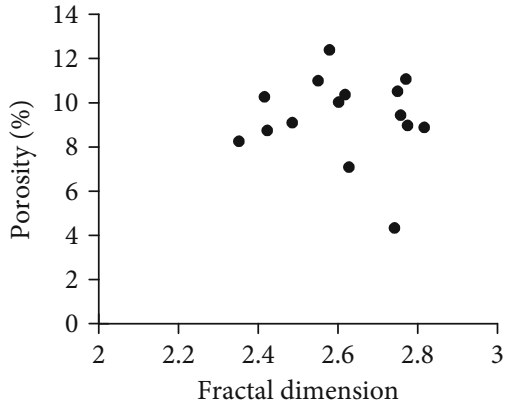

(b)

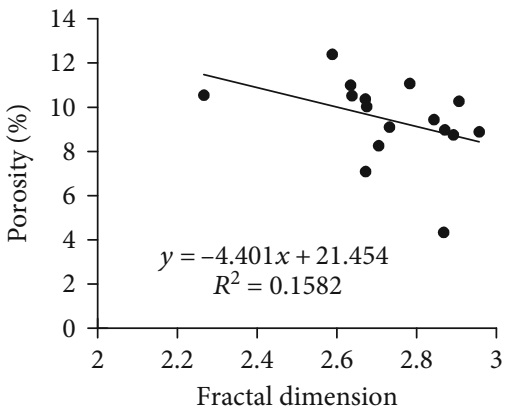

(d)

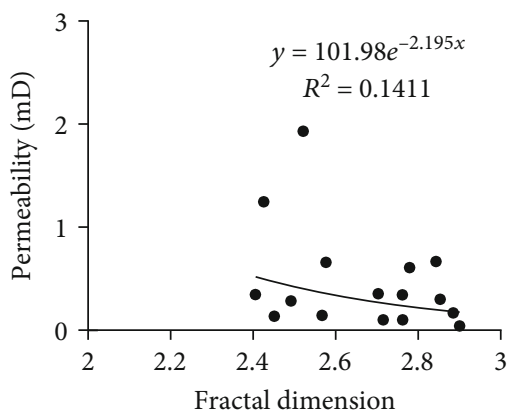

(f)

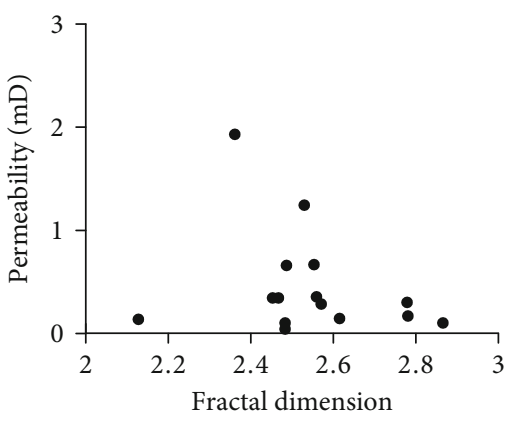

(h)

Figure 8: Continued. 


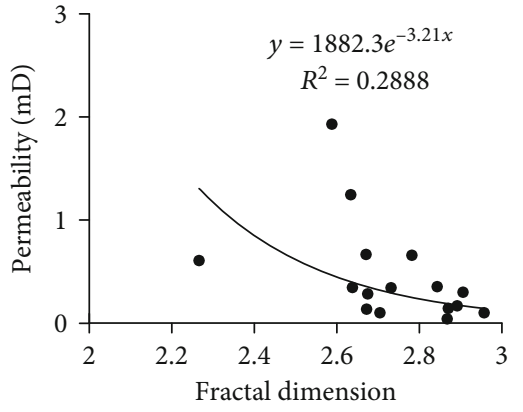

(i)

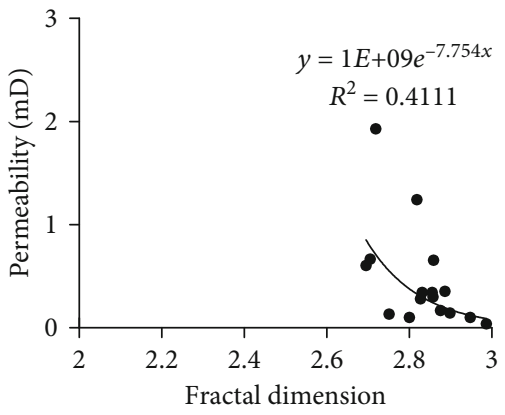

(j)

Figure 8: Correlations between fractal dimensions and physical properties. ((a-e) represent porosity while (f-j) represent permeability. Figures from the left to the right represent $D_{i 1}, D_{i 2}, D_{i 3}, D_{e 1}$, and $D_{e 2}$, respectively).

pores are rare in this type (short length of $D_{i 1}$ stage, $11.10 \%)$, and there is a distinct reflection point between $D_{i 2}{ }^{-}$and $D_{i 3}$-related segments $(27.86 \%$ and $61.04 \%$, respectively), which means that the dissolution pores and kaolinite-related pores are the dominant pore types (Supplementary Table 4 and Table 8; Figure 9(B-3)). There is a slight increase in threshold pressure while a moderate reduction in initial pressure of mercury withdrawal, manifesting that the pores are relatively large and nearly all of the mercury evacuated from the clay-related pores as the capillary pressure decreases (Figures 9(B-3) and 9(B-4)). The long $D_{e 1}$ stage corresponding to the kaolinite-related pores reveals that it occluded the massive throat spaces, and the weakness of the hysteresis is another evidence of the wellinterconnected pore throat and the considerable production of clay minerals (Figures 9(B-3) and 9(B-4)).

The primary interparticle pores were abundant in the throat-dominated reservoir type; however, the mica and pore-bridging clay minerals, especially pore-filling chlorite, resulted in the macroscale reduction of interparticle pores space, and the deterioration of reservoir quality was triggered by narrowed pores (porosity equal to $8.74 \%$ and permeability equal to $0.168 \mathrm{mD}$ ) (Figures $9(\mathrm{C}-1), 9(\mathrm{C}-2)$, and 10$). D_{i 3}$ are relatively large, and the length of narrowed/clay-related pores is relatively long (over 45\%) in this type of reservoir, which corresponds to the high proportion of narrowed pores and throats (Supplementary Table 4 and Table 8; Figures 9(C-3) and $9(\mathrm{C}-4))$. A strong hysteresis and medium-high percentage of clay-related pores indicate a limitation of mercury withdrawal due to poor pore-throat connectivity (Figure 9(C-3)). The inflection point of the mercury extrusion curve is ambiguous, testifying that the clayrelated pores have similar fractal dimensions with the interconnected pore throats (Figure 9(C-3)).

For the clay-related pore-dominated reservoir type, the interstitial minerals, especially dolomite, chlorite, and illite, intensively appeared (Figures $9(\mathrm{D}-1)$ and $9(\mathrm{D}-2)$ ). Illite is the most widely distributed clay mineral in this type, and it occurs as a pore-bridging interstitial fibrous and honeycombed cement (Figure 9(D-2)). Cementation by clay minerals leads to a reduction in porosity and permeability (Figure 10), which equal to $8.88 \%$ and $0.101 \mathrm{mD}$ in the typical sample, respectively. The clay-related pores occupied over
$50 \%$ of the total storage space based on the length of $D_{i 3}$ - and $D_{e 1}$-corresponding segments $(31.83 \%$ and $65.17 \%$, respectively), and the mercury extruded from the cores with the capillary pressure decrease at once has proven the equally intensive distribution of clay in this reservoir type (Supplementary Table 4 and Table 8; Figure 9(D-3)). Although the productive illite can compensate for the loss of porosity caused by mechanical compaction due to the spaces among the aggregates, the strong heterogeneous pore structure makes it hard to form commercial oil flow (Figures 9(D-3) and $9(\mathrm{D}-4)$ ).

The tight type is the worst reservoir type in a tight sandstone reservoir with quite low physical properties $(4.33 \%$ and $0.040 \mathrm{mD}$ in typical sample) due to densely distributed carbonate, especially ferrocalcite (Figures 9(E-1), 9(E-2), and 10). There are no obvious inflection points among interparticle, dissolution, and narrowed pore segments; only minor amounts of mercury could inject into the cores. The curve shows that partial percolations occur in the extremely high capillary pressure stage, which is contributed by microcracks resulting from strong mechanical compaction (Supplementary Table 4; Figures 9(E-3) and 9(E-4)). This type of tight sandstone has relatively high initial mercury extrusion pressure and strong hysteresis, indicating that few clay minerals existed (Figures 9(E-3) and 9(E-4)). The fractal dimensions $D_{e 1}$ represent the mercury withdrawal from microcracks in this reservoir type. The value of $D_{e 1}$ is larger than those of macro- and mesoscale pore samples (89.33\% when corresponding to the percentage of pores), manifesting that the microcracks can intensify the heterogeneity of the pore throats due to the differences of volumes between microcracks and conventional pores (Supplementary Table 4 and Table 8; Figures 9(E-3) and 9(E-4)). The largest $D_{e 2}$ value $(2.9873)$ can be seen as the proof of invalid interconnected pores due to the nonpercolation phenomenon with the diminution of capillary pressure (Figures 9(E-3) and 9(E-4)).

\section{Conclusions}

The fractal dimensions of tight sandstones from the Upper Triassic Yanchang Formation are segmented based on capillary pressure curves derived from HPMIP. The intrusion 

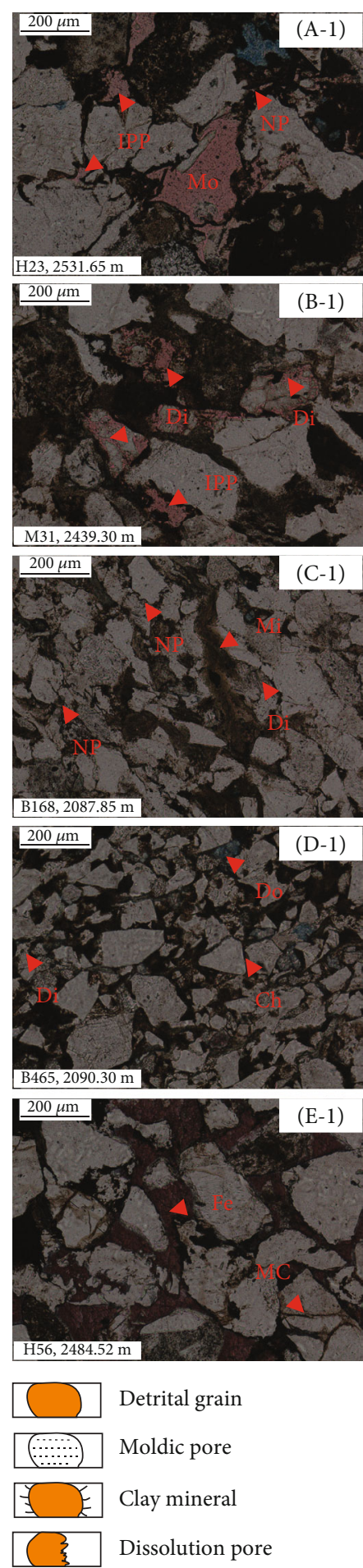
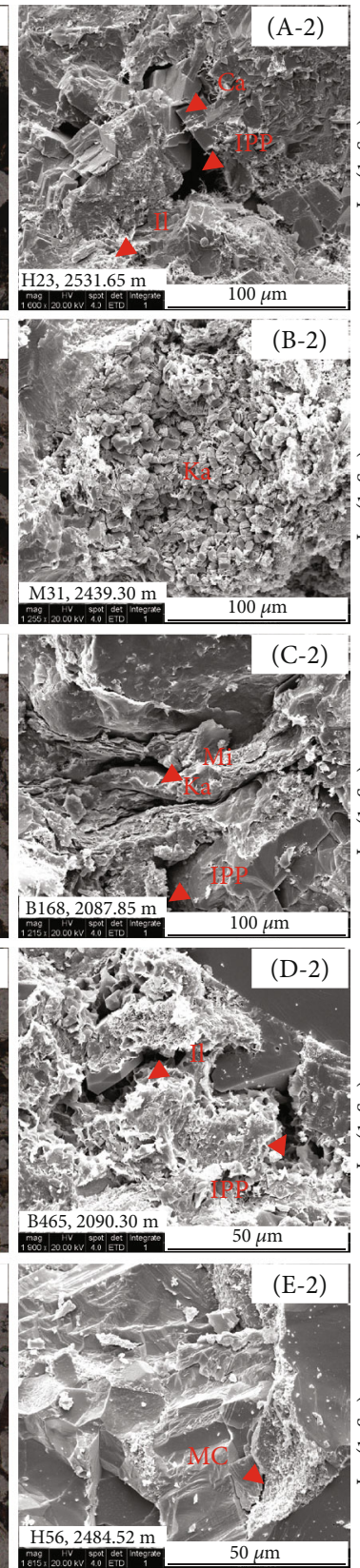
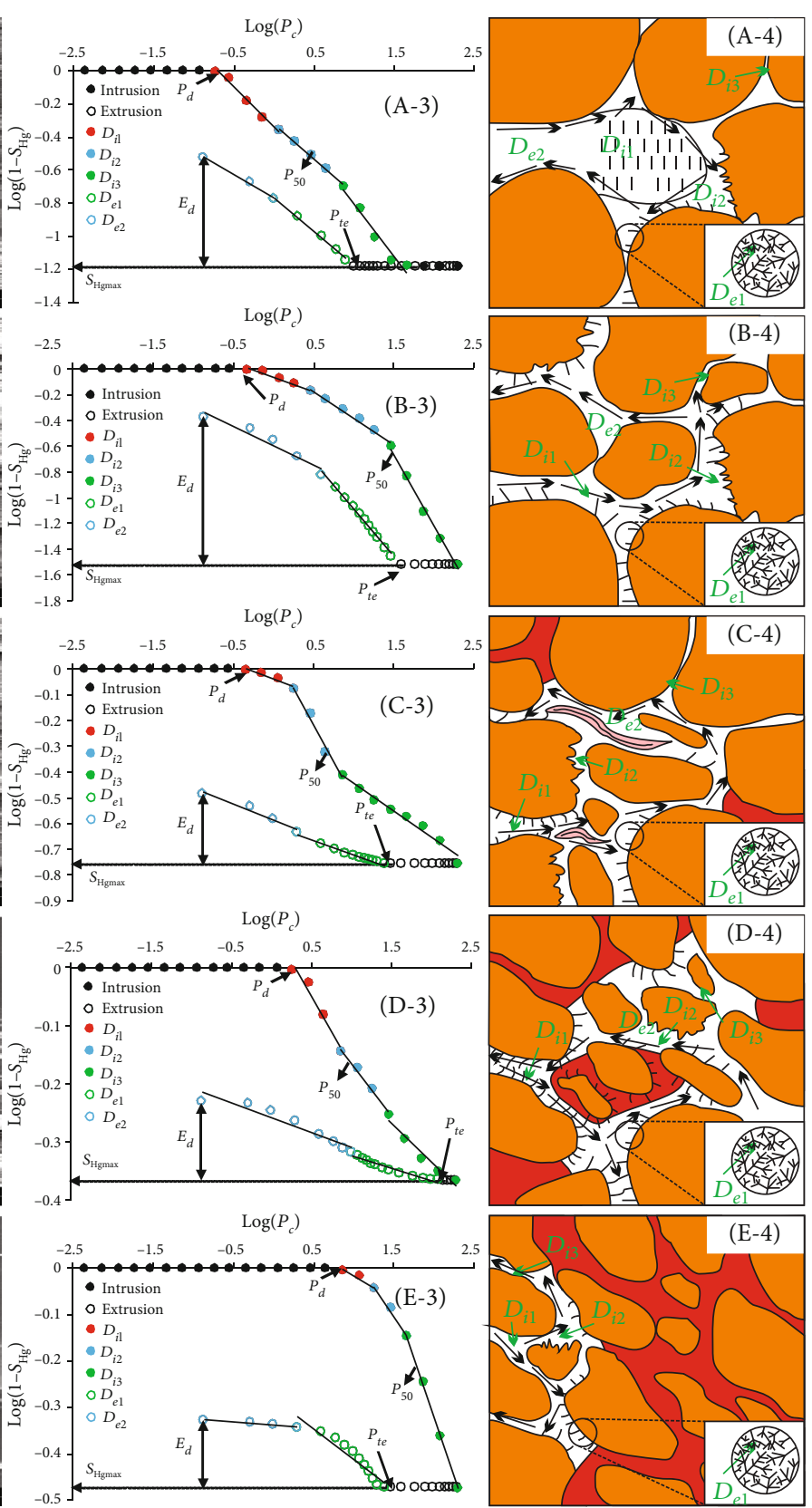

(霆空 Clay-related pore

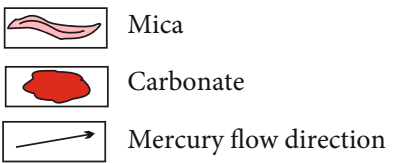

FIGURE 9: TS observation, SEM images, fractal dimensions from $\log \left(P_{c}\right)$ vs. $\log \left(1-S_{\mathrm{Hg}}\right)$ using HPMIP and schematic diagrams of HPMIPderived fractal dimensions and mercury flow. (A-1-A-4) Interparticle pore-dominated type; (B-1-B-4) dissolution pore-dominated type; (C-1-C-4) throat-dominated type; (D-1-D-4) clay-related pore-dominated type; (E-1-E-4) tight type. IPP: interparticle pore; Mo: moldic pore; NP: narrowed pore; Ca: carbonate; Il: illite; Di: dissolution pore; Ka: kaolinite; Mi: mica; Ch: chlorite; Do: dolomite; Fe: ferrocalcite; MC: microcrack.

curve can be divided into three ranges including $D_{i 1}, D_{i 2}$, and $D_{i 3}$, while the extrusion curve could be divided into two ranges, namely, $D_{e 1}$ and $D_{e 2}$, of which the former three ranges are acknowledged as interparticle pores, dissolution pores, and throats combined with voids among clay aggregates, respectively, and the latter two ranges are the representatives of clay-related pores and interconnected pore throats. 


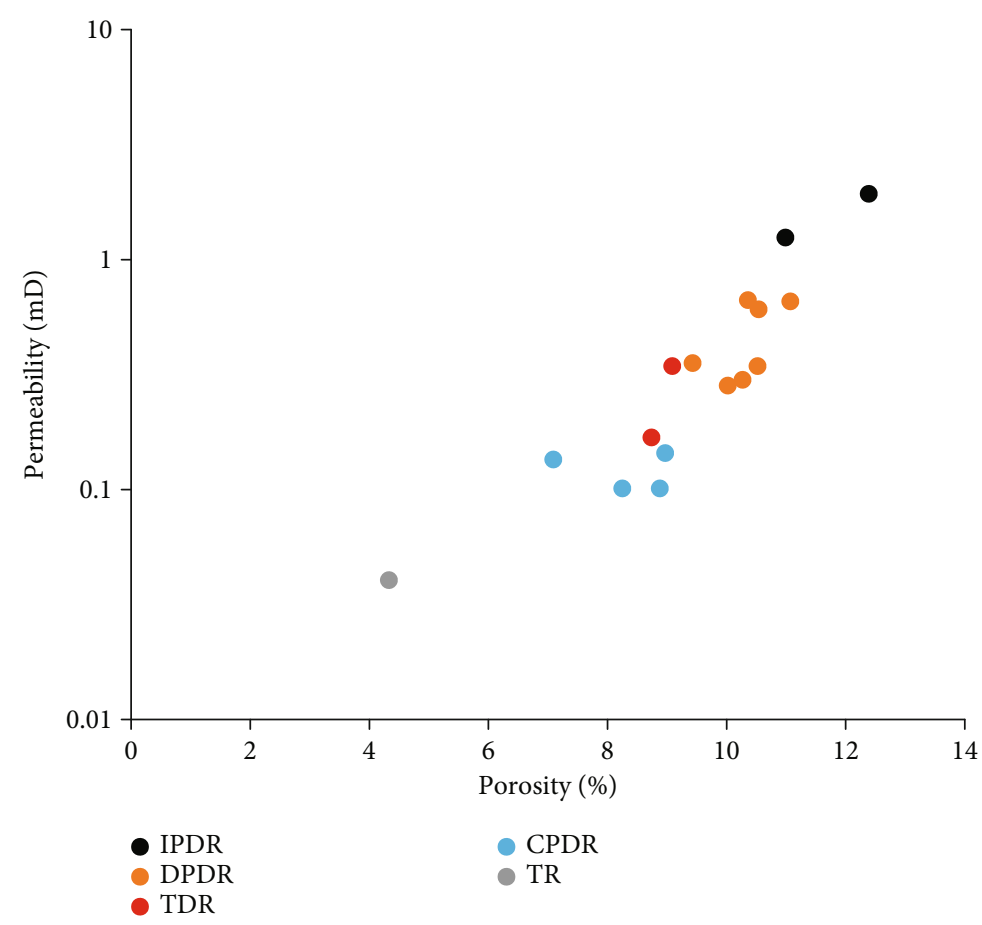

FIGURE 10: Porosity versus permeability of different types of reservoirs. IPDR: interparticle pore-dominated reservoir; DPDR: dissolution pore-dominated reservoir; TDR: throat-dominated reservoir; CPDR: clay-related pore dominated reservoir; TR: tight reservoir.

All HPMIP-derived parameters show relatively notable negative correlations with fractal dimension $D_{e 2}$. Threshold and median radius show relatively good correlations with $D_{i 1}$ while the correlations between the average radius and $D_{e 2}$ are relatively good. Fractal dimensions were more favorable to evaluate the complexity of the pore network compared with the skewness.

A high percentage of illite and carbonate minerals could deteriorate the pore-throat structure and enhance the heterogeneity of pore-throat systems. Vague correlations between fractal dimensions and detrital grain content which manifest as interstitial minerals are the decisive factor in PSD. With the increase of physical properties, pore-throat structures tend to be homogeneous.

According to petrographic observations and fractal characterization, five major reservoir types are defined, namely, interparticle pore-dominated, dissolution poredominated, throat-dominated, clay-related pore-dominated, and tight type, and the storage capacity decreases gradually. This work provides insights into determining the different reservoir types by more comprehensive ways, and it turns out that the fractal theory based on the multitype model was reliable, which favors the development of tight sandstones.

\section{Data Availability}

The experimental data used to support the findings of this study are included within the manuscript and the supplementary materials.

\section{Conflicts of Interest}

The authors declare that there are no conflicts of interest regarding the publication of this paper.

\section{Authors' Contributions}

Conceptualization was handled by Dengke Liu and Zhaolin $\mathrm{Gu}$; data curation by Dengke Liu and Ruixiang Liang; formal analysis by Dengke Liu and Ruixiang Liang; funding acquisition by Dazhong Ren, Chuanqing Huang, and Chao Yang; investigation by Dengke Liu and Junwei Su; methodology by Dengke Liu and Junwei Su; supervision by Zhaolin $\mathrm{Gu}$; figure drawing by Bin Chen; writing of the original draft by Dengke Liu; and writing, review, and editing by Junwei Su.

\section{Acknowledgments}

This work was supported by the Open Fund of Shaanxi Key Laboratory of Petroleum Accumulation Geology (No. PAG201901), the National Science and Technology Major Project (No. 2016ZX05047-003-005), the National Natural Science Foundation of China (Nos. 11872295 and 41702146), the Open Foundation of Shaanxi Key Laboratory of Lacustrine Shale Gas Accumulation and Exploitation (under planning) (No. YJSYZX18SKF0004), and the China National Petroleum Corporation's Basic Advanced Reserve Technology (No. 2018A-0908). 


\section{Supplementary Materials}

Supplementary material contains Table S1 to Table S8, which show the parameters derived from physical properties, TS, XRD, and HPMIP. (Supplementary Materials)

\section{References}

[1] C. Zou, R. Zhu, K. Liu et al., "Tight gas sandstone reservoirs in China: characteristics and recognition criteria," Journal of Petroleum Science and Engineering, vol. 88-89, pp. 82-91, 2012.

[2] R. Rezaee, A. Saeedi, and B. Clennell, “Tight gas sands permeability estimation from mercury injection capillary pressure and nuclear magnetic resonance data," Journal of Petroleum Science and Engineering, vol. 88-89, pp. 92-99, 2012.

[3] H. Huang, L. Chen, W. Sun et al., "Pore-throat structure and fractal characteristics of Shihezi formation tight gas sandstone in the Ordos Basin, China," Fractals, vol. 26, article 1840005, 2018.

[4] J. Su, G. Chai, L. Wang et al., "Direct numerical simulation of pore scale particle-water-oil transport in porous media," Journal of Petroleum Science and Engineering, vol. 180, pp. 159175, 2019.

[5] B. B. Mandelbrot, D. E. Passoja, and A. J. Paullay, "Fractal character of fracture surfaces of metals," Nature, vol. 308, no. 5961, pp. 721-722, 1984.

[6] F. Wang, K. Yang, J. You, and X. Lei, "Analysis of pore size distribution and fractal dimension in tight sandstone with mercury intrusion porosimetry," Results in Physics, vol. 13, p. 102283, 2019.

[7] R. Yang, S. He, J. Yi, and Q. Hu, "Nano-scale pore structure and fractal dimension of organic-rich Wufeng-Longmaxi shale from Jiaoshiba area, Sichuan Basin: investigations using FESEM, gas adsorption and helium pycnometry," Marine and Petroleum Geology, vol. 70, pp. 27-45, 2016.

[8] P. Li, M. Zheng, H. Bi, S. Wu, and X. Wang, "Pore throat structure and fractal characteristics of tight oil sandstone: a case study in the Ordos Basin, China," Journal of Petroleum Science and Engineering, vol. 149, pp. 665-674, 2017.

[9] Z. Zhang and A. Weller, "Fractal dimension of pore-space geometry of an Eocene sandstone formation," Geophysics, vol. 79, no. 6, pp. D377-D387, 2014.

[10] S. Zhou, D. Liu, Y. Cai, and Y. Yao, "Fractal characterization of pore-fracture in low-rank coals using a low-field NMR relaxation method," Fuel, vol. 181, pp. 218-226, 2016.

[11] J. W. Crawford, K. Ritz, and I. M. Young, "Quantification of fungal morphology, gaseous transport and microbial dynamics in soil: an integrated framework utilising fractal geometry," Geoderma, vol. 56, no. 1-4, pp. 157-172, 1993.

[12] P. Wang, Z. Jiang, W. Ji et al., "Heterogeneity of intergranular, intraparticle and organic pores in Longmaxi shale in Sichuan Basin, South China: evidence from SEM digital images and fractal and multifractal geometries," Marine and Petroleum Geology, vol. 72, pp. 122-138, 2016.

[13] K. Xi, Y. Cao, B. G. Haile et al., "How does the pore-throat size control the reservoir quality and oiliness of tight sandstones? The case of the Lower Cretaceous Quantou Formation in the southern Songliao Basin, China," Marine and Petroleum Geology, vol. 76, pp. 1-5, 2016.
[14] D. Xiao, S. Jiang, D. Thul, S. Lu, L. Zhang, and B. Li, "Impacts of clay on pore structure, storage and percolation of tight sandstones from the Songliao Basin, China: implications for genetic classification of tight sandstone reservoirs," Fuel, vol. 211, pp. 390-404, 2018.

[15] E. W. Washburn, "The dynamics of capillary flow," Physical Review, vol. 17, no. 3, pp. 273-283, 1921.

[16] I. M. K. Ismail and P. Pfeifer, "Fractal analysis and surface roughness of nonporous carbon fibers and carbon blacks," Langmuir, vol. 10, no. 5, pp. 1532-1538, 1994.

[17] A. L. Ahmad, N. F. Idrus, and S. R. Abd Shukor, "Surface fractal dimension of perovskite-doped alumina membrane: influence of calcining temperature," Journal of the American Ceramic Society, vol. 89, no. 5, pp. 1694-1698, 2006.

[18] L. Zhou and Z. Kang, "Fractal characterization of pores in shales using NMR: a case study from the Lower Cambrian Niutitang Formation in the Middle Yangtze Platform, Southwest China," Journal of Natural Gas Science and Engineering, vol. 35, pp. 860-872, 2016.

[19] A. Sakhaee-Pour and S. L. Bryant, "Effect of pore structure on the producibility of tight-gas sandstones," AAPG Bulletin, vol. 98, no. 4, pp. 663-694, 2014.

[20] K. Li, "Analytical derivation of Brooks-Corey type capillary pressure models using fractal geometry and evaluation of rock heterogeneity," Journal of Petroleum Science and Engineering, vol. 73, no. 1-2, pp. 20-26, 2010.

[21] S. Zhu, X. Wang, Y. Qin et al., "Occurrence and origin of pore-lining chlorite and its effectiveness on preserving porosity in sandstone of the middle Yanchang Formation in the southwest Ordos Basin," Applied Clay Science, vol. 148, pp. 25-38, 2017.

[22] H. Gao and H. Li, "Determination of movable fluid percentage and movable fluid porosity in ultra-low permeability sandstone using nuclear magnetic resonance (NMR) technique," Journal of Petroleum Science and Engineering, vol. 133, pp. 258-267, 2015.

[23] C. N. Zou, Z. Yang, S. Z. Tao et al., "Continuous hydrocarbon accumulation over a large area as a distinguishing characteristic of unconventional petroleum: the Ordos Basin, NorthCentral China," Earth-Science Reviews, vol. 126, pp. 358-369, 2013.

[24] Z. Lianbo and L. Xiang-Yang, "Fractures in sandstone reservoirs with ultra-low permeability: a case study of the Upper Triassic Yanchang Formation in the Ordos Basin, China," AAPG Bulletin, vol. 93, no. 4, pp. 461-477, 2009.

[25] W. R. Purcell, "Capillary pressures-their measurement using mercury and the calculation of permeability therefrom," Journal of Petroleum Technology, vol. 1, no. 2, pp. 39-48, 2013.

[26] A. Giri, S. Tarafdar, P. Gouze, and T. Dutta, "Fractal pore structure of sedimentary rocks: simulation in 2-d using a relaxed bidisperse ballistic deposition model," Journal of Applied Geophysics, vol. 87, pp. 40-45, 2012.

[27] J. Lai and G. Wang, "Fractal analysis of tight gas sandstones using high-pressure mercury intrusion techniques," Journal of Natural Gas Science and Engineering, vol. 24, pp. 185-196, 2015.

[28] Z. Yuan and P. C. Liu, "A new capillary pressure model using fractal geometry for coal porous media," Science Technology and Engineering, vol. 15, no. 9, pp. 63-67, 2015.

[29] R. L. Folk, Petrology of Sedimentary Rocks, Hemphill, Austin, TX, USA, 1974. 
[30] W. Huang, S. Lu, O. S. Hersi, M. Wang, S. Deng, and R. Lu, "Reservoir spaces in tight sandstones: classification, fractal characters, and heterogeneity," Journal of Natural Gas Science and Engineering, vol. 46, pp. 80-92, 2017.

[31] L. Wang, J. Su, Z. Gu, and L. Tang, "Numerical study on flow field and pollutant dispersion in an ideal street canyon within a real tree model at different wind velocities," Computers and Mathematics with Applications, 2020.

[32] G. Sheng, Y. Su, and W. Wang, "A new fractal approach for describing induced-fracture porosity/permeability/compressibility in stimulated unconventional reservoirs," Journal of Petroleum Science and Engineering, vol. 179, pp. 855-866, 2019.

[33] D. J. K. Ross and R. Marc Bustin, "The importance of shale composition and pore structure upon gas storage potential of shale gas reservoirs," Marine and Petroleum Geology, vol. 26, no. 6, pp. 916-927, 2009.

[34] Z. Chen, W. Jiang, L. Zhang, and M. Zha, "Organic matter, mineral composition, pore size and gas sorption capacity of lacustrine mudstones: implications for the shale oil and gas exploration in the Dongying depression, Eastern China," AAPG Bulletin, vol. 102, pp. 1565-1600, 2018.

[35] R. G. Loucks, R. M. Reed, S. C. Ruppel, and U. Hammes, "Spectrum of pore types and networks in mudrocks and a descriptive classification for matrix-related mudrock pores," AAPG Bulletin, vol. 96, no. 6, pp. 1071-1098, 2012.

[36] S. Shoval, "Deposition of volcanogenic smectite along the southeastern Neo-Tethys margin during the oceanic convergence stage," Applied Clay Science, vol. 24, no. 3-4, pp. 299311, 2004.

[37] G. Sheng, H. Zhao, Y. Su et al., "An analytical model to couple gas storage and transport capacity in organic matter with noncircular pores,” Fuel, vol. 268, p. 117288, 2020.

[38] M. R. Giles and R. B. De Boer, "Origin and significance of redistributional secondary porosity," Marine and Petroleum Geology, vol. 7, no. 4, pp. 378-397, 1990.

[39] K. Bjørlykke and J. Jahren, "Open or closed geochemical systems during diagenesis in sedimentary basins: constraints on mass transfer during diagenesis and the prediction of porosity in sandstone and carbonate reservoirs," AAPG Bulletin, vol. 96, no. 12, pp. 2193-2214, 2012.

[40] J. Su, G. Chai, L. Wang et al., "Pore-scale direct numerical simulation of particle transport in porous media," Chemical Engineering Science, vol. 199, pp. 613-627, 2019. 